\title{
ON THE EMERGENCE OF A GULF ENGLISH VARIETY: A SOCIOCULTURAL APPROACH
}

\author{
Nuha Suleiman Daoud Alshurafa \\ King Abdul-Aziz University
}

\begin{abstract}
The paper discusses the question of Linguistic identity in the Cooperation Council for the Arab States of the Gulf (henceforth CCASG). The notion of identity is analysed with reference to linguistic practices as a sociocultural means of communication. The existing register is a natural outcome on which the vast and fast process of modernization is reflected. The paper discusses a corpus of the Gulf register to seek an answer for the question of how the Arabic Gulf native identity impacts the English linguistic practice, as an interdisciplinary and integrative part in the sociocultural approach. Arabic meets with English as a global non-native variety of English and results in the new Gulf code. The result of the examination of linguistic practices confirm that identity in the Gulf reflects a cultural transformation and does not resist the new linguistic and sociocultural system. The selected theoretical framework for the analysis is drawn from a variety of linguistic subdisciplines and research traditions. The sociocultural approach is selected for this study as it is the most applicable.
\end{abstract}

Key Words: identity; Gulf Arab states; linguistic practices; sociocultural aspects; global English; Gulf register.

\section{INTRODUCTION}

The paper contributes to the notion of identity by providing the conceptualization of how the $21^{\text {st }}$ century sociocultural dynamics reveals a specific discourse by analyzing a collected data from the six Gulf States. The analysis confirms that identity in the Gulf reflects a cultural transformation instead of resisting this discourse, which is used as a means of communication, as a natural result of modernization/ globalization. The notion of identity emerges following this fast and vast development and is implemented in its positive aspect.

The spoken variety of English by natives in the Gulf used in this research is one of the communicative linguistic systems besides Arabic standard and spoken varieties. The new linguistic trend is an interdisciplinary and 
integrative approach of their native tongue, (Ager 1999; Bauman 2000; AlHalawani 2010; Jones 2007; Hassan 2010; and Al-Batal 2002). Al-Batal (2002) calls this type of identity in Lebanon: 'Lebanonism' which reflects within certain circles with "Arabism". By analogy to this, the English used in the Gulf by educated native adults of Arabic can be called "Gulfism".

The tested data distinguishes specific sociocultural phenomena that are reflected linguistically on the Gulf register character (or the "Gulfism" variety of global English). Some of these linguistic-sociocultural characterizations which reflect on the structure are like gender attitude difference; plural centered structure; linguistics and ideology; multilingual creativity; and the free insertion of some Arabic neutral expressions to the Gulf-English. These interactive linguistic features are evidences to demonstrate the retention rather than the loss of the native Gulf identity of the sociocultural aspects in this vast and fast age of modernization. The map below presents the location of the Arab Gulf States involved in the topic of discussion in this paper:

\section{Map (1): The Arab Gulf States}

Source: Peck (2007).

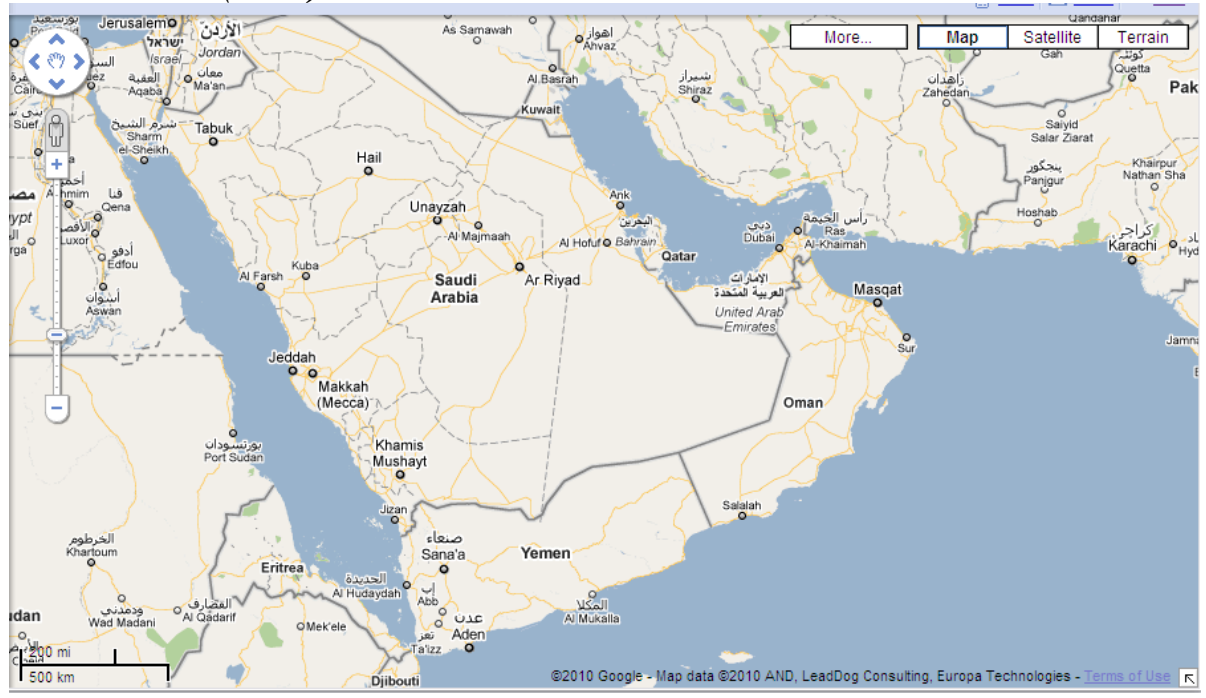

The map above (1) contains the six Arab Gulf States of the GCC created on $25^{\text {th }}$ May, 1981, and which are: Bahrain; Saudi Arabia; Qatar; Kuwait; Oman; and the United Arab Emirates. Standard Arabic is the official language there, and each state is distinguished by its own variety of spoken Arabic. English is the "lingua Franca" for communication, and Standard English is taught at schools and universities as a second language and the language of science and technology and other fields of knowledge, (El-Sanabary 1992; Findlow 2006; Gordon 1985; Hassan 2010; Holes 1987; Jones 2007; and Peck 2007). 


\section{IDENTITY AND LINGUISTIC-SOCIOCULTURAL DUALISM IN THE GULF: RELATED BACKGROUND}

The English variety used by the native Gulf Arabs implies the Gulf region and identity. Although there has been no sociocultural analysis implemented on this topic prior to this study, it has been a case supported by many scholars, each one in the related context. The quotations below are found applicable where it provides an implicit presentation of why people in the Gulf region identify with this variety of English.

For example, Al-Halawani (2010) says that language and nation are the identity of people. Thus, society at large, and the Gulf is a case in point, culture determines identity, (Dhillon 2009; Kachru et al. 2009; Valentine 2009; Mesthrie 2008; and Crystal 2004 and 2007). Crystal (2004: 129) mentions that one of the purposes of language is to express identity, another is to foster mutual intelligibility. Concerning ethics, identity according to Pagliai (2002), is always shifting, bipolar or multipolar, dual or multiple.

Individuals are members of the linguistic community, with language pointing to their identity. While identity has been a widely circulating notion in sociocultural research topic for some time, the present study offers one way of understanding this body of work by anchoring identity in interaction. The concept tries to provide an explicit theorization through analyzing the English corpus as used by natives of Arabic in the Gulf region.

Identity does not emerge at a single analytic level- whether turn shape, code choice, or ideological structure- but operates at multiple levels simultaneously. It works at an intellectual level in order to gain social meaning. To achieve our goal here; namely: to describe the linguisticsociocultural identity in the Gulf, traditional scholarly view of identity is used. According to this view, identity is located primarily within the individual's mind, so that relationship between identity and language use is for language to reflect the individual's internal mental state, (Johnston 1996). Accordingly, the social ground is discounted where identity is formed inside the mind and is then expressed via discourse, (Ager 1999; Bauman 2000; Jaff 2000; Butcholtz and Hall 2005; Johnston 1996).

In the Gulf region, Arabic meets with English and the description of the Globalisation of English as a non-native variety applies best here, (Mesthrie and Bhatt 2008; Kachru et al. 2009; Al-Shurafa 2009). A modernized language variation according to Holes (1987: 19) 'is an evidence of a coexistence and mutual communication of language system'. This type of language represents a managed register that alternates with certain variety of English which leads to the use of the existing register in the Gulf.

New Englishes have arisen because of the need to express national identity, (Crystal 2004:36). The making of these varieties of English worldwide is imposed by the need for identity. Thus, this linguistic diversity is 
essential to all kinds of environment because language lies at the heart of what it means to be human, (Crystal 2004: 90-98). English in certain territories has public and administrative roles without formal colonization like in Oman and Qatar, (Mesthrie and Bhatt 2008: 31).

Identity construction is a central part of this process which arises in the linguistic-cultural dualism within a set of hierarchies, (Mesthrie and Bhatt 2008: 143). The recognition of the fact that language has many functions is based on an intellectual basis on a global scale. The sense of local identity (Crystal 2007:176) is reflected on the system of education and the sociocultural communication with one another, among other things where the linguistic medium is English. The resulting linguistic-sociocultural dualism offers insights for potential cultural transformation that resists identity construction, (Findlow 2006). A bilingual policy allows people in the Gulf to look both linguistic-cultural ways which seems to be efficient to mark the Gulf identity of the $21^{\text {st }}$ century.

English is increasingly becoming the pervasive language (Kachru et al. 2009; Langendoen 2001; Crystal 2007; Findlow 2006). It is a natural consequence to prevail in most educational institutions and schools as well as social and various contexts of situations in the Gulf. On a general scale, there is rarely any excitement involved in using or learning only Arabic, (Hassan 2010; El-Sanabary 1992) as compared to English's creative and constantly updated approaches. It is the language of the internet and of our entire intellectual make up, (Crystal 2004 and 2007).

\section{RELATED LITERATURE}

Our own view of identity has been informed through a wide variety of research in several linguistic interdisciplinary fields. Such work includes social identity theory (Mayerhoff 1996; Mayerhoff and Niedzielski 1994; and Tafjel and Turner 1997); models of identity (Le Page and Tabouret-Keller 1985) and local identity (Crystal 2004 and 2007; Hassan 2010; and AlHalawani 2010) gender identities (Valentine 2009) in sociolinguistics; and hybrid identity (Jaff 2000) in bilingual linguistics and metalinguistic cultural repertoire, among others. Butcholtz and Hall (2005) provide a framework for the analysis of identity in sociocultural linguistic approach which relates here. They defined five principles base to analyze identity as produced in linguistic interaction where identity is theorized as a broader intersubjective phenomenon than simply individualistic and deliberate action. It is generally a relation between self and others of the overlapping aspects of the individual intentionality, which may be in part intentional and in part habitual and less than fully conscious. 


\section{THE THEORETICAL FRAMEWORK OUTLINED}

The selected theoretical framework for the analysis is drawn from a variety of linguistic subdisciplinary and research traditions among which are the linguistic discourse and the sociocultural aspects. The sociocultural approach is selected for this study as it is the most applicable. Linguistic theories are thought to be especially relevant to an understanding of the construction of identity within the informal interactional contexts. Moreover, the framework we outline here synthesizes key works from all the consulted literature traditions to offer a general sociocultural linguistic perspective on identity. It is entailed in language and applies to the socioculture where language, culture and society interact. Such interdisciplinary fields involve sociolinguistics, conversation analysis and linguistically oriented sociocultural and social analysis. The diverse approaches incorporate to acknowledge language and identity in their full range of central linguistic phenomenon.

\section{DATA/ ANALYSIS}

\subsection{Data}

Theoretically, the paper engages with a dynamic discussion of a collected corpus from various naturally occurring conversations of social contexts in a number of Gulf States; namely: Kuwait, Saudi Arabia, Qatar, Oman, The United Arab Emirates and Bahrain. Data provide a true reflection of the prevailing creative multi-lingual and global variety of English sociocultural register. Educated adults, males and females constitute the subjects, and the data have been collected by the author's personal observation and occasional recording upon personal consequential visits between 2003-2010 to the Gulf States. The total number of data are six hundred clauses collected from the six states equal in terms of size. Extracts from the data include the discussed linguistic characters of identity. The basic reason is specifically that the discussed sociocultural aspects are shared phenomena in the Gulf.

\subsection{Analysis and Discussion}

The analysis of the data below are devoted to examine identity in the Gulf and how cultural transformation are reflected on the new linguistic and sociolinguistic system as a natural outcome of the social shift. The underlying theoretical constraint of Arabic language structure influences the internal structure of the Global English variety in the Gulf. Accordingly, identity is dealt with by people's awareness rather than resistance of the involved sociocultural aspect of modernization.

The five sub-sections below discuss selected extracts that best represent the linguistic production of the Gulf-English natives' variety. The selected 
characteristics for discussion are believed to reflect the basic features of identity in the Gulf-English of the linguistic-socioculture repertoire. The five basic features are presented and discussed in turn with reference to the corresponding extractions in the subsections below.

\subsubsection{Gendered Attitudinal Difference and Identity}

The first feature is related to Gender. This is a familiar idea discussed in different branches of sociocultural linguistics, (Bucholtz et al. 2005, West and Zimmer 1987). Despite the fact that there are six Gulf states involved, this aspect of identity is found to be similar and the data include similar attitudinal aspect. The examples below occur in various Golf State, and only the gender of the speaker is disclosed for the interest of the research discussion:

\section{(1) We all have this common enemy. (female)}

The female uses we (instead of I) in order to refer to herself. This self consciousness has a frequent recurrence in the data. The above example also has all as a confirmation of the conscious attitudinal difference of gender which is used basically by females.

In contrast, the following utterance is used by a male:

(2) Hello guys! And of course I am the only guy over here, and I feel lonely. (male)

The first person singular pronoun I occurs twice. The statement carries the strong and sure tone of the male confirming male dominance.

The following are more examples, as in:

(3) Today's topic is something we actually didn't talk about before. (female)

(4) You go in the car and the guy is coming to you... (a male addresses all females)

(5) I'm doing something to save our memory. (female)

Statements (3) and (5) as used by females contain we and our respectively, where in both sentences the females meant to say: (I) and (my). Sentence (4) contains the masculine tone which firmly addresses the females' addressee, where you occurs twice.

The following interesting exchange occurs between a male and a female:

(6) a. How are you X?

(male)

b. Hi! How are you?

(female) 

c. Pretty good!
(same male)
d. Yea! That's good!
(same female)

The female is submitting to the gender attitudinal male dominance by not replying to the question, in (6.b) whereas the male is sure and firm in his reply, as in (6.c). She is a recipient as in (6.b\&d) while he is the leader as in (6.a \& c). Similar contexts of situation on world Englishes and gender identity have been discussed (Al-Halawani 2010:1; Valentine 2009: 568; Bucholtz and Hall 2005: 590).

When the speaker assigns social gender to another one, the masculine form is almost always selected no matter what the gender of the speaker is, as in:

(7) Suppose he ( they) will go shopping twice this week. (female)

(8) You can call me through the email now. (male)

(9) I'm taking about.... We're talking about... (female)

(10) Somebody cuts you off with a car. Do you get all mad? And ... what is he doing and he doesn't know how to drive? You are frustrated. You get down, and ... you are ready for a physical fight. (male addressing all females)

In similar contexts as (7) above, the reference varies between he $\sim$ they, with the percentage of $57.3 \% \sim 42.7 \%$ respectively, according to a count carried out on the collected data. Females tend to go for the subconscious choice of he more frequently. The male in (8) above has the masculine strong and the voice of confidence expressed by his order 'to call', using me and not bothering to insert any phrase of 'courtesy'. A similar attitudinal aspect is realized in (10) above, where the same speaker addresses females only. He is presupposing that the driver is a 'male' although the conversation took place in Qatar where both genders drive. Finally, the hesitant female in (9) above once uses I, but uses we in the same statement where she refers to herself.

Nearly all contemporary linguistic research on identity takes this perspective of gender as its starting point, (Bucholtz et al. 2005: 588). Cases of gender identity illustrate in various ways the male dominant society, and women and men hold different feelings which are reflected in their linguistic choices. Gender does make a difference in language choice and in the construction of identity, (Valentine 2009: 570), and the Gulf English variety is no exception

\subsubsection{Plural-Centered Structure}

The pluralistic (or the potential for pluricentricity) perspective tends to occur with females, (Valentine 2009: 569). This feature occurs remarkably in our data. The view of the distinctive cultural identity or 'cultural emblems' 
(Kachru 2000:18), is found to be central for a continual re-evaluation not only in world Englishes but also in the Gulf variety of English.

The linguistic pluralism is an accepted norm within the world Englishes paradigm where women creativity occurs (Valentine 2009: 568). Thus, terms such as 'pluricentrism' among others attest to those expressions of the global lingua franca (Valentine 2009: 569).

Below are some excerpts from our data where females' speeches embody the pluralistic perspective, as in:

(11) Welcome back to our wonderful cooking session. (female)

(12) Can you help explain that to us? (female)

(13) It came as a shock to many of us as others hated us. (female)

(14) He is a well known artist. He himself came ... (male)

(15) I'll give you fifty percent discount for this! (male)

(16) Yes! A man who lost his son... (male)

All the female's extracts above involve the plural personal pronouns reference; namely: our in (11), and us once in (12) and twice in (13) where the speaker means to refer to her 'single' self. Whereas the male speeches above, collected from different Gulf States, uses the firm tone with the singular pronoun references, as He occurs twice and himself occurs once in (14), as well as I in (15) above. In (16), his choice of gender is man / his which interrelates to the above sub-section's topic on the masculine gender attitude selection.

The extracts below are two more examples of the potential pluricentricity choice, as in:

(17) Today, we have another couple of dishes ... (female)

(18) Our guest is umm-Khalid (the mother of Khalid) has just joined us. (female)

The female speaker uses all three first person plural inflections, as we in (17), our and us in (18) above to refer to herself, the singular reference instead.

The data also include alternation between the plural and the singular third person forms with reference to both genders, as in: (female)

(20) ... but guys, you are talking about. (a female addressing females)

(21) When you are talking about someone. (a male addressing females) 
The female uses the neutral reference person in (19), and guys in (20) to address the females. The male address es the females by using you in (21) above. Both males and females use person, guys and someone to address both genders and is accepted by all.

\subsubsection{Ideology and the Linguistic-sociocultural practices}

Within the World Englishes' paradigm, language and ideology are integral in understanding the changing roles and functions in the global lingua franca, (Valentine 2009: 267, Bucholtz and Hall 2005: 590). The Gulf variety of English is invaded by religious terms and expressions with specific meaning. Elements of Gulf religious ideology are drawn on by the natives of the Gulf in order to locate themselves within (or against) independent ideologies.

The following are illustrative examples:

(22) Wallah (i.e. I swear by Allah) you'll feel a lot better.

(23) I'm confident with God's assistance that the truth will come out.

(24) They will declare their engagement soon. Insha'Allah (i.e. Allah willing).

Three different expressions are used in each one of the above examples which are directly borrowed from religion. The expressions are commonly used in the Gulf locals' mother tongue and are directly interpreted and used in the Gulf English variety. These are: Wallahi (i.e. I swear by Allah), with God's help, and Insha'Allah (i.e. Allah willing) in (22), (23) and (24) respectively.

Ideological idiomatic expression are also used, as in the following:

(25) I mean, honestly, let's say ...

(26) God knows how.

The above expressions directly meet with the natives' ideology. Honestly and God knows in (25) and (26) respectively, are direct interpretations of the sociocultural identity using these linguistic expressions.

\subsubsection{Multilingual Creativity}

Emblematic (Kachru 2000: 18) grammatical structures such as the zero copula among others (for more syntactic discussion see Al-Shurafa 2009), are understood to belong to this categorized characteristic. These features are also referred to as creative linguistic expressions.

Below are selected representative extracts: 
(27) You and he is ready for a physical fight.

(28) Himself, he comes from nowhere! No origin!

The usages of is in (27), and of himself and he in (28) above are creations by the nonnative English users in the Gulf of one variety of the world Englishes. Moreover, 'the fluidity within the world Englishes framework allowed new approaches to bend and sway with the many expressions of English around the world', (Valentine 2009: 567).

Below are more examples with different creations:

(29) Why [---] they do this to me?

(30) Why is this is the right place to do that?

While there is no verb in (29), two forms of the copula is are inserted in (30) above. The data contains various examples and the above selected ones represent the central creativity of this perspective.

\subsubsection{Free insertion of Arabic expressions}

Though limited to certain Arabic expressions, the natives in the Gulf tend to insert certain neutral Arabic terms into the English variety. What is interesting is that native English and Americans living there start to use these terms in their proper contexts.

The following is an extracted sentence from the data:

$$
\text { ... and all those stuff, ya3ni, they aren't any good. }
$$

where ya3ni means (I mean), and is an expression for clarification. It also means (actually) in similar contexts and is a common expression in Arabic where it is inserted freely in the Gulf English variety. The -Identity of the Gulf natives is explicit as well as retained."

The following extract contains a different Arabic expression:

You are understanding, maashi?

The Arabic expression maashi (literally, [he is] going), which means $(\mathrm{OK})$ and is used when the speaker seeks the hearer's approval.

The expression below contains a common greeting expression in the Arab World:

(33) $\operatorname{Salaam}(\mathbf{z})$ 
The (z) is freely attached to indicate the plural. This form of salutation seems to receive a positive reaction of approval and replaces words for greeting such as (hello) (Hi) and even (bye).

Finally, it is noticed in the data that whenever an Arabic expression or a lexical form is inserted, the equivalent corresponding English term is immediately provided. The following are representative examples: .. a wonderful yellow pigment of turmeric or kurkum as is called in Arabic.

(35) I read the other day that kammoon or cumin has a lot of health properties.

(36) Take a bit of heated khubz or bread ...

So, the English equivalent term immediately preceeds as in (34) above, or follows as in both (35) and (36) to ensure clarity. These terms and the like culture specific terms are interpretations of the cross cultural analysis of identity.

\section{CONCLUSION}

The general conclusion of the analysis confirms the need to accept change in language as a normal process with a positive impact on identity in the Gulf. The data reveals that the Gulf identity is constituted through the dualism of linguistic-sociocultural characteristics. Cases of gender identity in the Gulf illustrate in various ways the male dominance society, where women and men hold different feelings which are reflected in their linguistic choices. Gender makes a difference in language choice and in the construction of identity.

The pluralistic (or the potential for pluricentricity) perspective tends to occur with females. This feature of identity in the Gulf occurs frequently in our data. The view of this distinctive cultural identity is found to be central for a continual re-evaluation not only in world Englishes but also in the Gulf variety of English.

Language and ideology are integral in understanding the changing roles and functions in the global lingua franca and mark the Gulf variety of English. It is invested with religious terms and expressions with specific meaning. Elements of Gulf religious ideology are drawn on by the natives of the Gulf in order to locate themselves within (or against) other ideologies. These expressions are found to be direct interpretations of the sociocultural identity by using the explicit linguistic expressions.

Creative linguistic expressions or emblematic (Kachru 2000: 18) grammatical structures are like the use of the zero copula among others. Finally, though the free insertion of Arabic expressions is limited to certain Arabic expressions and certain educated people, the natives in the Gulf tend to 
insert certain neutral Arabic terms into the English variety which is another aspect of the interpretation of the cross cultural analysis of the Gulf identity. What is interesting is that some native English and Americans living in this region also tend to use these terms in their proper contexts.

The research comes up with the suggestion that this type of identity in the Gulf be called English Gulfism by analogy to 'Lebanonism' and 'Arabism'.

\section{REFERENCES}

Ager, Dennis.1999. Identity, Insecurity and Image: France and Language. Cleve done: Multilingual matters.

Al-Batal, Mahmoud. 2002. 'Identity and Language Tension in Lebanon: the Arabic Local News in LBC1'. Rouchdy, Aleya (ed) 'Language Contact and Language Conflict in Arabic: Variations on a sociolinguistic Themes. Rutledge Curzon: 91-115.

Al-Halawani, Raghda. (16 ${ }^{\text {th }}$ Jan., 2010. "The Battle for Egypt Identity", in Gulf News: 1 .

Al-Shurafa, Nuha Suleiman. 2009. 'Linguistic Variation and Use of the $21^{\text {st }}$ Century Arabicization of English.' Applied Linguistic Conference, 27-28 $8^{\text {th }}$ March, Oxford University, UK.

Bauman, Richard. 2000. 'Language, Identity, Performance.' in $\operatorname{IPrA}$ (International Pragmatic Association) 10(1), Antwerp: 1-7.

Bucholtz, Mary and Kira Hall. 2005. 'Identity and Interaction: A Sociocultural Linguistic Approach' in Discourse Studies 7(4-5): 585-614.

Crystal, David. 2004. The Language Revolution. Cambridge; polity Press Ltd. 2007. English as a global Language. Cambridge: Cambridge University Press.

Dhillon, Pradeef A. 2009. 'Colonial Critique: The Challenge from World Englishes' in Kashru, Braj B; Yamuna Kashru and Cecil L. Nelson (eds). The Handbook of World Englishes. Oxford: Willy-Blackwell: 529-566.

Dutkova-Cope, Linda. 2002. 'Texas Czech Folk Music and Ethnic Identity' in IPrA (International Pragmatic Association) 10(1). Antwerb: 7-37.

El-Sanabary, Nagat. 1992. Education in the Arab Gulf States and the Arab World, an annotated Bibliographic Guid. New York: Garland Publishing, Inc.

Findlow, Sally. 2006. 'Higher Education and Linguistic Dualism in the Arab Gulf.' British Journal of Sociology of Education, Vol. 27(No.1). Rutledge, February: 19-36.

Gordon, David. 1985. 'The Arabic Language and National Identity: The Case of Algeria and of Lebanon.' Jacob, J.E. and W.R. Beer (ed) Language Policy and National Unity. New Jersey: Rowan and Allan held Publishers: 134-150. 
VOLUME 7

Hassan, Bahaa-eddin abulhassan. 2010. 'Language and Identity: Impact of Globalization on Arabic.' Round Table 2010: Arabic Language and Linguistics. Georgetown University, March, 12-14.

Holes, Clive. 1987. Language Variation and Change in a Modernising Arab State: The Case of Bahrain. London: Kegan Paul International.

Jacob, J.E. and W.R. Beer (ed). 1985. Language Policy and National Unity.

New Jersey: Rowan and Allan held Publishers.

Jaff, Alexandra. 2000. 'Comic Performance and the Articulation of Identity' in IPrA (International Pragmatic Association) 10(1). Antwerp: 39-59.

Johnstone, B. 1996. The Linguistic Individual: Self Expression in Language and Linguistics. New York: Oxford University Press.

Jones, T. 2007. Arabian Gulf States Postal History. U.S. Class publication.

Kachru, Braj B. 2000. 'Asia's Englishes' in Englishs Today 16(1): 17-22.

Kachru, Braj B., Yamouna Kashru and Cecil L Nelson. 2009. The Handbook of World Englishes. Oxford: Wiley-Blackwell.

Langendeon, Terrence. 2001. ' Linguistics at the beginning of the $21^{\text {st }}$ Century.' Aronoff, Mark Janie Rees-Miller (ed) The Handbook of Linguistics. Malden, MA and Oxford: Blackwell publishers: XVI +824 .

Le Page, R. B. and A. Tabouret-Keller. 1985. Acts of Identity Creole-Based Approaches to Language and Ethnicity. Cambridge: Cambridge University Press.

Li, Jaun. 2009. 'Intertextuality and National Identity: Discourse of National Conflict in Daily Newspapers in the U.S and China' in Discourse and Society 20(1). Saint Thomas University, U.S.A: 85-121.

Mayerhoff, M. 1996. 'Dealing with Gender and Identity as a Sociolinguistic Variable' in Bergvall, V. L.; J. M. Bing and A. F. Freed (eds) Rethinking Language and Gender Research: Theory and Practice. London: Longman: 202-227.

Mayerhoff, M. and N. Niedzielski. 1994. 'Resistance to Creolization: An Interpersonal and Intergroup Account' in Language and Communication 14(4): 313-330.

Mesthrie, Rajend and Rakesh M. Bhatt. 2008. World Englishes: The Study of the New English Varieties. Cambridge: Cambridge University Press.

Mufwene, Salikoko S. 2002. 'Colonization, Globalization and the Plight of "Weak" Languages' in Journal of Linguistics 38. Cambridge: Cambridge University Press375-395.

Nettle, Daniel and Suzanne Romaine. 2000. Vanishing Voices: The Extinction of the World's Languages. Oxford: Oxford University Press.

Pagliai, Valentina. 2000. 'Lands I Came to Sing: Negotiating Identities and Places in the Tuscan "Contrasto"' in IPrA (International Pragmatic Association) 10(1). Antwerp: 125-146.

Peck, Malcolm C. 2007. Historical Dictionary of the Gulf Arab States. The Scarecrow Press. 
Romanie, Suzanne. 2009. 'Language, Culture and Identity: Issues across Nations' in Banks, Jane (ed). Rutledge International Companion to Multicultural Education. (Chapter 27). London: Rutledge: 373-384.

Tafjel, H. and Turner, J. C. 1997. 'An integrative Theory of Intergroup Conflict' in W. G. Austin and S. Worchel (eds) The Social Psychology of Intergroup Relations. Monterey, CA: Books/Cole: 33-47.

Valentine, Tamara M. 2009. 'World Englishes and Gender Identity' in Kashru et al. (eds). The Handbook of World Englishes. Oxford: Wiley-Blackwell: 567-580.

West, C. and D. H. Zimmerman. 1987. 'Doing Gender' in Gender and Society 1(2):125-151. 